\title{
Metadiscourse Devices in E-mail Writing: A Case Study Between a Polish Teacher and a Chinese Student
}

\author{
Tian Huiling \\ Department of Linguistics, Three Gorges University, Yichang, China
}

Email address:

15586378047@163.com

To cite this article:

Tian Huiling. Metadiscourse Devices in E-mail Writing: A Case Study between a Polish Teacher and a Chinese Student. International Journal of Language and Linguistics. Vol. 3, No. 3, 2015, pp. 187-192. doi: 10.11648/j.ij11.20150303.22

\begin{abstract}
This article aims at reporting on some of the preliminary results of an on-going study on the difference of the use of metadiscourse strategies in e-mail writing between a Polish teacher and a Chinese student. Drawing on Hyland's (2005) Metadiscourse Theory, the purpose of the analysis is to show how the use of metadiscourse devices varies between an English-speaking person and a non English-speaking person in e-mail writing which covers a time period from 9 December 2013 to 1 January 2014. According to the analysis, we found out that metadisourse devices are frequently used in E-mail writing. Thanks to the different thinking mode and different ideology, people from different countries may use metadisourse devices differently. For example, the Polish Peter used more engagement markers than the Chinese student Tina did. While Tina used more hedges than Peter did. In this whole process, culture plays an important role.
\end{abstract}

Keywords: Metadiscourse Device, E-Mail Writhing, Case Study

\section{Introduction}

The purpose of the study is to analyze the difference of the application of metadiscourse devices between an English-speaking person and a non English-speaking person in e-mail writing. E-mail writing is a special way of communication, and it is also a way to build and maintain personal relationship. The analysis is a single case study based on observation of a total of $16 \mathrm{e}$-mails selected from a database of 142 e-mails. According to Hyland (2008), the essence of metadiscourse is that communication is more than a way to convey information, goods or services, but is also involves the personalities, attitudes and assumption of the speakers. $\mathrm{He}$ further classified metadiscouse into interactive and interactional dimensions (Hyland and Tse, 2004). The study of this article is carried out from both these two dimensions. I hope this study can be helpful to the successful communication between people from different countries. Under the guidance of the difference of the use of metadisourse devices, the two speakers can understand each other smoothly.

\section{Introduction to the Texts}

The texts I have chosen are 16 e-mails selected from a total of 142 e-mails written by a teacher and a student. The teacher is a 75-year-old Polish male who works as a teacher in a University and lives alone in China. His name is Peter. He only teaches postgraduate students who major in English. The courses he teaches involve Research Methodology, General Linguistics and Sociolinguistics. The language he applies is English. The student is a Chinese female postgraduate student of the first year and majors in English. Her name is Tina. She is 24 years old and local to the city she studies in. The e-mails were written in English by the same two people. The time period of the e-mails selected covers almost a month, which is from 9 December 2013 to 1 January 2014. The time period of the total 142 e-mails is from 8 August 2013 to 26 May 2014. Since the two people are still contacting, the total number is improving. The 16 e-mails were selected because of the event that the student helped the teacher find a new apartment to live in, since the landlord of his original apartment planned to sell the apartment and hence urged the teacher to move out within a month. The whole event includes contacting the new landlord who released the renting House Rental Advertisement on the internet, seeing the house, negotiating with the owner, moving in and unpacking. The event ended with cleaning up the new apartment. 


\section{Analytical Framework}

The concept I found useful to my study is Hyland's (1998) "Metadiscourse Theory". The term of "Metadiscourse" was firstly put forward by the American linguist Harris (1959). It aroused numerous interests in the field of applied linguistics. After more than twenty years' development, the study of Metadisourse has already become an energetic field (Adel, 2006). Then with its development, the study on Metadiscourse from the perspective of passage has been gradually accepted by scholars (Mauranen, 2010). Hyland developed the study on Metadiscourse and put forward Metadiscourse Theory. Hyland's (1998) analytical framework is built on the basis of Crismore, Markkanen, and Steffense (Hyland, 2005, p.49). According to Hyland (2008), the term "metadiscourse" means the linguistic expressions which refer to the evolving text and to the writer and imagined readers of that text. The concept of metadisourse is on the basis of writing as social engagement. It shows the writer's awareness of the unfolding text as discourse: how we situate ourselves and our readers in a text to create convincing, coherent prose in a particular social context. Although there is no strict definition of what is metadisourse, scholars divide it into generalized metadiscourse and narrow metadiscourse (Adel, 2010). What we are talking about here is narrow metadiscourse. There are also some scholars (Del Saz
Rubio 2011, Gillaerts \& Vande Velde 2010, Kim \& Lim 2013, Li \& Wharton 2012, Fu \& Hyland 2014, Salas 2015) studying metadiscourse from the perspective of the text inside, which is targeting at the discourse itself, the author as well as the reader of the discourse.

Based on the conception of Thompson and Thetela (1995), Hyland (2004) further categorized metadisourse into interactive metadiscourse resources and interactional metadiscourse resources. The interactive dimension concerns the writer's awareness of the imagined readers and the ways he or she conveys its probable knowledge, interests, rhetorical expectations and processing abilities. Here, the goal of the writer is to shape a text which meets the needs of particular readers and on the other hand set out arguments so that readers can recover the writer's preferred interpretations and goals. The interactional dimension concerns the way writers conduct interaction, by intruding and commenting on their message (Hyland, 2005, p.49). Here, the writer is aimed at making his or her idea explicit and involving readers by allowing them to respond to the unfolding text. In a word, interactional resources reveal the extent to which the writer works to jointly construct the text with readers.

The coding schema in table 1 is based on the above categorization and it is employed to analyze 22 e-mails.

Table 1. Coding schema for metadiscourse; (based on Hyland, 2005, p.49).

\begin{tabular}{|c|c|c|}
\hline Category & Function & Examples \\
\hline Interactive & Help to guide the reader through the text & Resources \\
\hline Transition & express relations between main clauses & in addition; but; thus; and \\
\hline Frame markers & refer o discourse acts, sequence or stages & finally; to conclude; my purpose is \\
\hline Evidentials & refer to information from other texts & according to $\mathrm{X} ; \mathrm{Z}$ states \\
\hline Code glasses & elaborate propositional meanings & namely; e.g; such as ; in other words \\
\hline Interactional & Involve the reader in the text & Resources \\
\hline Boosters & emphasize certainty or close dialogue & in fact; definitely; it is clear that \\
\hline Attitude markers & express writer's attitude to proposition & unfortunately; I agree; surprisingly \\
\hline Self mentions & explicit references to author(s) & I; we; me; our \\
\hline Engagement markers & explicitly build relationship with reader & consider; note; you can see that \\
\hline
\end{tabular}

\section{Analysis}

According to the deep analysis of 16 e-mails, we found out that metadiscourse devices were frequently used in e-mail writing, with a total use of 143 times of two speakers in the whole process (see table 1).

Table 2. Total metadiscourse in e-mail.

\begin{tabular}{lllll}
\hline Categories & Peter & \multicolumn{3}{c}{ Tina } \\
\hline Interactive devices & 20 & $33.9 \%$ & 25 & $29.8 \%$ \\
Interactional devices & 39 & $66.1 \%$ & 59 & $70.2 \%$ \\
Total & 59 & 100 & 84 & 100 \\
\hline
\end{tabular}

From table 2, we can see that in e-mail writing, both two speakers used more interactional devices than interactive devices, which is because the interactional dimension is the writer's expression of a textual 'voice', or community-recognized personality, and includes the ways he or she conveys judgments and overtly aligns him or herself with readers (Hyland, 2008, p49). In interactive dimension, the author focuses more on the way to organize the texts. E-mail writing is a way to communicate with each other and to convey information, thus it requires enough interaction between the writer and the reader; it has a lot to do with reader involvement. In this sense, interactional devices are more frequently used in e-mail writing. Another point that needs to be noticed is that Tina (a total of 84 times) apparently used more metadiscourse devices than Peter did (a total of 59 times). According to Hyland (2005:37), metadiscourse is to help the writer (or speaker) to express a viewpoint and engage with readers as members of a particular community". With the application of metadiscourse theory, our communication can be facilitated, viewpoints supported, readability improved and relationships maintained. The reason why Tina used more metadiscourse is that she was a non English-speaking student. On one hand, she paid more attention to the way she spoke, so she used more 
metadiscourse in case that her information was not successfully conveyed; on the other hand, as in China, there is certain boundary between the role of a teacher and a student. Student should show absolute respect to the teacher. In this sense, Tina tended to use more discourse devices to show her respect, such as hedges.

Table 3. detailed metadiscourse in e-mail writing.

\begin{tabular}{lllll}
\hline \multirow{2}{*}{ Categories } & Peter & \multicolumn{3}{c}{ Tina } \\
\cline { 2 - 5 } & Frequency & Percentage & Frequency & Percentage \\
\hline Transitions & 13 & $22 \%$ & 17 & $20 \%$ \\
Frame & 6 & $10 \%$ & 8 & $9.5 \%$ \\
markers & & & & \\
Enphoric & 0 & 0 & 0 & 0 \\
markers & 0 & 0 & 0 & 0 \\
Evidentials & 0 & $1.0 \%$ & 0 & 0 \\
Code glosses & 1 & $11.9 \%$ & 20 & $24 \%$ \\
$\begin{array}{l}\text { Hedges } \\
\text { Boosters }\end{array}$ & 2 & $3.3 \%$ & 0 & 0 \\
$\begin{array}{l}\text { Attitude } \\
\text { markers }\end{array}$ & 0 & 0 & 1 & $1.1 \%$ \\
$\begin{array}{l}\text { Self mentions } \\
\text { Engagement }\end{array}$ & 20 & $33.9 \%$ & 31 & $36.9 \%$ \\
markers & 10 & $16.9 \%$ & 7 & $8.3 \%$ \\
\hline
\end{tabular}

Table 3 is the detailed analysis of the use of all kinds of metadiscourse devices in e-mail writing. From table 3, we can see that compared with others, enphoric markers, evidentials, code glosses, attitude markers were seldom used in e-mail writing, which is caused by the functions of these three devices. Endophoric markers are expressions which refer to other parts of the text. These expressions can make additional material stand out and hence available to the reader in aiding the recovery of the writer' meanings, often facilitating comprehension and supporting arguments by referring to earlier material of anticipating something yet to come. Endophoric markers are often used in academic writing. The function of evidentials is mainly providing important support for arguments. So evidentials are mainly used in argumentative writing. Code glosses are expressions used by rephrasing, explaining or elaborating what has been said to supply additional information. They are more frequently used in expository writing. Hedges, transitions, frame markers, self-mentions and engagement markers are relatively frequently used. Among these, self-mentions are most frequently used by both two speakers, with the number of 20 and 31. All writing carries information about the writer, but the convention of personal projection through first-person pronouns is perhaps the most powerful means of self-representation (Ivanic, 1998). To make a clear statement of self-representation, the speakers tend to use more self-mentions. This is the same case in e-mail writing. Both two speakers chose to use more self-mentions to stand for their grounds and identity.

To make a comparison between two speakers, we can see the big difference of the use of metadiscourse devices lies in the use of hedges, self-mentions and engagement markers. From table 3, we can see that Tina used more hedges (24\%) than Peter did (11.9\%); she also used more self-mentions (36.9\%) than Peter did (20\%). In contrast, Peter used more engagement markers (16.9\%) than Tina did (8.3\%). Hedges are expressions such as possible, might and perhaps, which indicate the writer's tendency to recognize alternative voices and ideas and so withhold complete commitment to a position (Hyland, 2008: 52). Hedges emphasize the uncertainty of the opinion. Writers must calculate what weight to give an assertion, considering the degree of precision or reliability that they want it to carry and perhaps claiming projection in the event of its eventual overthrow (Hyland, 1998a). Here, since Tina is a non English-speaking student, she has less confidence in expressing herself in English context. While Peter has no this kind of worries. What's more, it also accounts for Chinese culture. In traditional Chinese culture, we value a lot of the conserved principles. So we should be euphemistic when we are talking in case we offend others. We have curved thinking mode. While westerners have linear thinking mode, they tend to speak more directly and show their full involvement with the speaker, which is why Peter used more engagement markers than Tina did. According to Hyland (2008), engagement markers are expressions that explicitly address readers, either to focus their attention or include them as discourse participants. It is an important way to build good personal relationship between two speakers.

Table 4 is a further comparison of the use of "I" and "We" between two speakers. We can see that there exists obvious difference of first-person pronouns of Peter. In the whole process, he used 16 times of "I" and only used four times of "We". Tina used 12 times of "We" and used 19 times of "I".

Table 4. Comparison of the use of "I" and "We" between two speakers.

\begin{tabular}{lll}
\hline Categories & Peter & Tina \\
\hline $\mathrm{I}$ & 16 & 12 \\
$\mathrm{We}$ & 4 & 19 \\
\hline
\end{tabular}

\section{Conclusions}

Since two speakers come from different countries, have different languages, they have different cultures, which lead to the difference of the use of metadiscourse devices between two speakers. To be detailed, the influence of the culture on the use of metadiscourse can be seen in two ways. On one hand, the difference in their thinking mode leaded to the different use of hedges and engagement markers. As a typical example of traditional Chinese culture, Tina had imagery, stereoscopic and especially circular thinking mode. So she was used to detour. She might put more emphasis on thinking in images and was used to use metaphor; she might pay more attention to Heaven and harmony. On the contrary, westerners had abstract, creative and linear thinking mode, which can be shown by Peter. They tended to speak directly and come straight to the point; they liked to define things. In the whole process of e-mail writing, the use of more hedges by Tina was the reflection of her circular thinking mode. She used hedges to show respect, show discretion and uncertainty. Peter tended to use fewer hedges and more engagement markers, for he preferred to use bluntness and directness to show his idea.

On the other hand, the difference of their values resulted in 
the different frequency of the use of "I" and "We" between two speakers. According to Hofstede's(2002) findings, westerner countries tend to value individualism. For members of extreme individualist cultures, individual rights and obligations comes first. There is a strong emphasis on individual merit and competition. These culture stress individual initiative and achievement, and they value individual decision. While counties like Pakistan, Japan and China value collectivism. In these countries, a "we" consciousness prevails: identity is based on the social system; the individual is emotionally dependent on organizations and institutions; the culture emphasizes belonging to organization. From table 3, we can see Peter used only 4 times "we", compared with Tina's 19 times. This is because as a member of westerners, Peter valued a lot of individualism. He had "I" consciousness rather than "we" consciousness. Tina's use of more "we" was the reflection of her value in collectivism.

The article made a deep analysis of the use of metadisourse devices between two speakers who had different nationalities. It found out that they shared some similarities. Such as, both of them used more interactional devices in e-mail writing; both of them seldom used boosters and attitude markers, which are related to their functions. There were differences in some respects as well, which is my focus in this paper. Firstly, the English-speaking Peter used more engagement markers than the non English-speaking Tina. While Tina used more hedges than Peter did. This is resulted from their different thinking modes. Secondly, we found out that Tina used more "I" than "we", while Peter is on the contrary. It is their different values made the difference. Peter values individualism, while Tina values collectivism. According to the analysis, we can see that metadiscourse devices are frequently used in e-mail writing. Different people may choose different devices in communication; culture plays an important role in this process.

\section{Appendix}

\section{On 8 December 2013 06:17}

Dear Peter,

This is Tina's composition. Thank you for your time and patience!

By the way, Jane told me what has happened about the apartment. I am sorry to hear that. But don't worry.

If you are not satisfied with the house you are supposed to see tomorrow, we will then negotiate with the owner of the apartment we saw yesterday. I can see the possibility of signing the contract within six months if we strongly require it. We can discuss it after you see the house tomorrow.

your sincerely,

Tina

\section{On 8 December 2013 2:59pm}

Dear Tina,

Thank you so much for your help!

I will try and see this other apartment today or tomorrow, then we can come to a decision.

See you tomorrow.

Warmest regards,

Peter

\section{On 9 December 2013 06:31am}

Dear Peter,

I just called the owner of the apartment and asked him whether he can change the renting period as six months. He said he would discuss with his wife and then give me reply tomorrow. I will tell you as soon as I know it. Please don't worry, we students are all here for you!

Your sincerely,

Tina

\section{On 13 December 3:33pm}

Dear Tina and Thomasa,

I think the best, if possible, would be to move most of the boxes and some of the furniture on Monday 23rd or, if that is not convenient, on the Tuesday or Thursday (Wednesday is Christmas Day). After that I will doubtless be heading for Shenzhen.

Everything is very flexible. Just tell me what you arrange.

If possible, I would keep the bed and my desk till early January.

Five of the second year want to help me pack next weekend (Wang Jing and some others) so all the boxes, or most of them, should be ready by Monday.

Love, Peter

\section{On 13 December 2013 21:02pm}

Dear Peter,

We will collect more empty boxes on this weekend and bring them to you on Monday 16th. I guess we may not keep the bed till January.cause when you are back from Shenzhen,there are few students here, most of them will be back at home, and it will be hard for you to find a hand. The telephone numberyou gave me last time and told him the situation of the big stuff like bed and refrigerator. I asked him whether he can borrow a little truck or something like that. He said that he would check it and then give me reply on Monday16th. We can discuss the details further once I get his reply.

Your sincerely,

Tina

\section{On 15 December 2013 21:35}

Dear Peter,

Johnny said he would not be off work until $6 \mathrm{pm}$. So he may not join us for dinner on Wednesday in case students wait him for a long time.

We fixed the time as tommrow. He will come to your apartment as soon as he finishes his work at $6 \mathrm{pm}$. And then we can go to the dinner. Or we first have dinner then see your apatment, both OK. What do you think? 
your sincerely,

Tina

\section{On 15 December 2013 9:40pm}

Dear Tina,

Both are OK.

You and Johnny decide.

Just let me know.

Peter

\section{On 15 December 2013 23:00pm}

Dear Peter,

We chose the first option. He will arrive at your apartment and see the stuff by himself around 6:30pm. Then go for supper.

\section{On 16 December 2013 1:11am}

Dear Tina,

I will be waiting for you.

I presume you will show Johnny the way.

He has never been to my place.

Looking forward to seeing you tomorrow evening!

\section{On 22 December 2013 06:12am}

Dear Peter,

OK. I will bring someone tomorrow. But I am not available for dinner, cause I have a date tomorrow night. Thank you all the same. See you tomorrow.

Tina

\section{On 22 December 2013 2:02 pm}

Dear Tina,

You can always bring your date:-)

Thomasa said she would bring Vicky and Cynthia. It would be good to bring another person if you can.

Peter

\section{On 25 December 2013 0:28 am}

Dear Tina and Thomasa,

Thank you for your kind invitation tomorrow night but I simply have too much to do before I leave for Shenzhen early Saturday morning. Life is a little hectic at the moment, not just because of my packing.

I hope you have a wonderful time at your party.

I will let you know next week how much help I will need for the move on the 2 nd. I do not think many people will be needed as there will mainly be the heavy stuff to move and two of the boyfriends of third year students have volunteered to help Johnny.

Love, Peter

\section{On 30 December 2013 01:08}

Dear Peter,

Johnny said he has workers to move the stuff, so he only needs two interpreters. The one who is in your original apartment is supposed to tell them what should be moved, the other one who is in the new apartment can tell the workers where they should put the stuff. I guess people are far enough, if Thomasa, me, three of the third year,one boyfriend all included. Maybe we don't need so many people. Four is ideal. What do you think?

Love, Tina

\section{On 30 December 2013 1:18am}

Dear Tina,

That sounds marvellous.

I will suggest that just two of the third year come. If they still do want to come, they can start on the last thing which will be the kitchen and which I will finish clearing before I hand over the apartment officially on Monday.

Love, Peter

\section{On 1 January $201417: 59$ pm}

Dear Peter,

Johnny said the remover would be leaving at 2:30, the same time when Thomasa and I leave dorm. They may arrive at your place by 3:00. See you afternoon!

Love, Tina

\section{On 1 January 2014 9:00pm}

Dear Tina,

Your work is independent of the removers so come at the time that suits you.

It is mainly concerned with packing and transporting kitchen stuff

Some of the third year will be coming at 2.0

Love, Peter

\section{References}

[1] Adel, A. Metadiscourse in L1 and L2 English [J]. Nordic Journal of English Studies, 2006, p. 69-97.

[2] Adel, A. Metadiscourse: Diverse and divided perspectives [J]. Nordic Journal of English Studies, 2010, p.1-11.

[3] Del Saz Rubio, M. A pragmatic approach to the macro-structure and metadiscoursal features of research article introductions in the field of Agricultural Sciences [J]. English for Specific Purposes, 2011, (4): 258 - 271.

[4] Fu, X. \& K. Hyland. Interactions in two journalistic genres: A study of interactional metadiscourse[J]. English Text Construction, 2014, (1): $122-144$.

[5] Gillaerts, P. \& F. van de Velde. Interactional metadiscourse in research article abstracts [J]. Journal of English for Academic Purposes, 2011, (2): 128 -139.

[6] Harris, Z. Linguistic transformations for information retrieval $[J]$. In Proceedings of the International Conference on Scientific Information, Vol. 2. Washington D. C: National Academy of Science -National Research Council (NAS-NRC). 1959. 
[7] Hyland, K. Persuasion and context: The pragmatics of academic metadiscourse [J].Journal of Pragmatics, 1998, p.437- 455 .

[8] Hofstede. Convergence and divergence in consume behavior: implication for international retailing [J].Journal of Retailing, 2002 (5).

[9] Hyland, K. \& P. Tse. Metadiscourse in academic writing: A reappraisal [J].Applied Linguistics, 2004, p.156- 177.

[10] Hyland, K. Metadiscourse, exploring interaction in writing. London: Continuum, 2005.

[11] Hyland, K. Metadiscourse. Beijing: Continuum, 2008.

[12] Kim, L. \& Lim, J. Metadiscourse in English and Chinese research article introductions [J]. Discourse Studies, 2013, (2): $129-146$.
[13] Li, T. \& Wharton, S. Metadiscourse repertoire of L1 Mandarin undergraduates writing in English: A cross-contextual, cross-disciplinary study $[\mathrm{J}]$. Journal of English for Academic Purposes, 2013, (4): 345 - 356.

[14] Mauranen, A. Discourse reflexivity-a discourse universal? The case of ELF [J]. Nordic Journal of English Studies, 2010, p.12-40.

[15] Sala, M. Reflexive metadiscourse in research articles in Spanish: Variation across three disciplines (linguistics, economics, and medicine) [J]. Journal of Pragmatics, 2015, (77): 20 - 40.

[16] Thompson, G. \& Thetala, P. The Sound of One Hand Clapping: the Management of Interaction in Written Discourse [J]. Text, Vol. 15 (1), 1995, p.103-127.

[17] Williams, M. Style: Ten Lessons in Clarity and Grace [J]. Boston: Scott Foresman, 1981. 